INSTITUT NATIONAL DE LA STATISTIQUE ET DES ETUDES ECONOMIQUES

Série des Documents de Travail du CREST

(Centre de Recherche en Economie et Statistique)

\author{
$n^{\circ}$ 2002-11 \\ Testing Contract Theory : \\ A Survey of Some Recent Work
}

\author{
P. A. CHIAPPORI \\ B. SALANIE ${ }^{2}$
}

Les documents de travail ne reflètent pas la position de l'INSEE et n'engagent que leurs auteurs.

Working papers do not reflect the position of INSEE but only the views of the authors.

\footnotetext{
* We thank our discussant Patrick Legros and Jeff Campbell, Pierre Dubois, Philippe Gagnepain, Lars Hansen, Jim Heckman, Bruce Shearer, Steve Tadelis and Rob Townsend for their comments. This paper was written while Salanié was visiting the University of Chicago, which he thanks for its hospitality.

1 Department of Economics, University of Chicago, USA.

2 CREST, CNRS and CEPR, Paris.
} 


\title{
Testing Contract Theory: A Survey of Some Recent Work ${ }^{1}$
}

\author{
P.A. Chiappori ${ }^{2}$ \\ B. Salanié ${ }^{3}$
}

March 2002

${ }^{1}$ We thank our discussant Patrick Legros and Jeff Campbell, Pierre Dubois, Philippe Gagnepain, Lars Hansen, Jim Heckman, Bruce Shearer, Steve Tadelis and Rob Townsend for their comments. This paper was written while Salanié was visiting the University of Chicago, which he thanks for its hospitality.

2 Department of Economics, University of Chicago.

3 CREST, CNRS and CEPR, Paris. 


\title{
Résumé
}

Cet article présente une revue de la littérature récente sur l'évaluation empirique de la théorie des contrats. Nous examinons l'effet des incitations sur le comportement des agents et l'optimalité des contrats réels en insistant particulièrement sur l'importance d'une bonne prise en compte de l'hétérogénéité individuelle.

\begin{abstract}
This paper presents a survey of the recent literature on the empirical evaluation of contract theory. We discuss the effect of incentives on behavior and the optimality of real-world contract. We stress particularly the importance of properly taking into account unobserved heterogeneity.
\end{abstract}




\section{Introduction}

It is a capital mistake to theorise before one has data.

Arthur Conan Doyle, A Scandal in Bohemia.

Since the early seventies, the development of the theoretical literature on contracts has been nothing short of explosive. The study of more and more sophisticated abstract models has gone hand in hand with the use of the tools of the theory to better understand many fields of economics, such as industrial organization, labor economics, taxation, insurance markets or the economics of banking. However, it is only fair to say that the empirical validation of the theory has long lagged behind the theoretical work. Many papers consist of theoretical analyses only, with little attention to the facts. Others state socalled stylized facts often based on fragile anecdotal evidence and go on to study a model from which these stylized facts can be derived. Until the beginning of the eighties, empirical tests using actual data and econometric methods were very rare, even though the theoretical literature had by then given birth to a large number of interesting testable predictions.

While such a long lag is not untypical in economics, it is clearly unfortunate, especially when one compares our practice to that of other scientists. Even without fully sharing the somewhat extreme methodological views expressed above by Sherlock Holmes, one can hardly dispute that interactions between theory and reality are at the core of any scientific approach. To give only one example, the models of insurance markets under asymmetric information developed at the beginning of the seventies were only extensively tested (and found to lack empirical support) in the middle of the nineties. If this had been done earlier, the twenty-year period could have been used to devise better models.

Fortunately, a number of empirical researchers have turned their attention to the theory of contracts in recent years, so that such long lags should become less common. This survey will present a panorama of this burgeoning literature. Because new papers are appearing every week in this field, we cannot claim to be exhaustive. We just hope that we can convey to the reader both a sense of excitement at these recent developments and an understanding of the specific econometric problems involved in taking contract theory to the data.

A unifying theme of our survey is the necessity of controlling adequately for unobserved heterogeneity in this literature. If it is not done properly, then the combination of unobserved heterogeneity and of endogenous matching of agents to contracts is bound to create selection biases on the parameters of interest. This is given a striking illustration in a recent contribution by Ackerberg and Botticini (forthcoming). They consider the choice between sharecropping and fixed rent contracts in a tenant-landlord relationship. Standard moral hazard models stress the trade-off between incentives and risk-sharing in the determination of contractual forms. Fixed rent contracts are very efficient from the incentives viewpoint, since the tenant is both the main decision maker and the residual claimant. However, they also generate a very inefficient allocation of 
risk, in which all the risk is borne by one agent, the tenant, who is presumably more risk averse. When uncertainty is small, risk sharing matters less, and fixed rent contracts are more likely to be adopted. On the contrary, in a very uncertain environment, risk sharing is paramount, and sharecropping is the natural contractual form. This prediction can readily be tested from data on existing contracts, provided that a proxy for the level of risk is available. For instance, if some crops are known to be more risky than others, the theory predicts that these crops are more likely to be associated with sharecropping contracts.

A number of papers have tested this prediction by regressing contract choice on crop riskiness. The underlying argument, however, has an obvious weakness: it takes contracts as exogenously given, and disregards any possible endogeneity in the matching of agents to contracts. In other words, the theoretical prediction described above only holds for given characteristics of the landlord and the agents. It can be taken to the data only to the extent that this "everything equal" assumption is satisfied, so that agents facing different contracts do not differ by some otherwise relevant characteristic. Assume, on the contrary, that agents exhibit ex ante heterogeneous degrees of risk aversion. To keep things simple, assume that a fraction of the agents are risk neutral, while the rest are risk averse. Different agents will be drawn to different crops; efficiency suggests that risk neutral agents should specialize in the more risky crops. But note that risk neutral agents should also be proposed fixed rent contracts, since risk sharing is not an issue for them. Thus given heterogeneous risk aversions, fixed rent contracts are associated with the more risky crops, and the standard prediction is reversed.

Clearly, the core of the difficulty lies in the fact that although risk aversion plays a crucial role in the story, it is not directly observable. Conditional on risk aversion, the initial theoretical argument remains valid: more risk makes fixed rent contracts look less attractive. This prediction can in principle be tested, but it requires that differences in risk aversion be controlled for in the estimation or that the resulting endogeneity bias be corrected in some way.

The paper is divided in two parts. In section 2, we study the effect of contractual forms on behavior. This obviously comprises the measure of the socalled "incentive effect", i.e. the increase in productivity generated by moving to a higher-powered incentive contract; but we adopt a more general approach here. Thus we consider that the decision to participate in a relationship or the choice of a contract in a menu of contracts all are effects of contractual forms on behavior. Section 3 turns to the optimality of observed contracts. The central question, here, can be stated as follows: does the theory predict well the contractual forms that we actually observe? Section 4 provides a brief conclusion.

Contract theory encompasses a very large body of literature, and we had to make choices in order to keep a manageable length for this survey. First, we only consider situations where contracts are explicit and the details of the contractual agreement are available to the econometrician. In particular, we do not cover the literature on optimal of risk-sharing within a group, that has rapidly developped 
since the initial contributions of Cochrane (1991) and Townsend (1994) ${ }^{1}$. There are also areas where excellent surveys of the empirical literature have been written recently. Thus we will not mention any work on auctions in this survey, and we refer the reader to Laffont (1997). Similarly, we will only briefly touch on the provision of incentives in firms, which is discussed by Prendergast (1999) and Gibbons and Waldman (1998).

\section{Contracts and behavior}

Circumstantial evidence is a very tricky thing. Arthur Conan Doyle, The Boscombe Valley Mystery.

Several papers aim at analyzing the links between the form of existing contracts and observed behavior. A recurrent problem of this literature is related to selection issues. Empirical observation provides direct evidence of correlations between contracts and behavior. Theoretical predictions, on the other hand, are concerned with causality relationships. Assessing causality from correlations is an old problem in economics, and indeed in all of science; but the issue is particularly important in our context. Typically, one can observe that different contracts are associated with different behaviors, as documented by a large number of contributions. But the interpretation of the observed correlations is not straightforward. One explanation is that contracts induce the corresponding behavior through their underlying incentive structure; this defines the so-called incentive effect of contracts. However, an alternative, and often just as convincing story is that differences in behavior simply reflect some unobserved heterogeneity across agents, and that this heterogeneity is also responsible for the variation in contract choices.

Interestingly enough, this distinction is familiar to both theorists and econometricians, although the vocabulary may differ. Econometricians have for a long time stressed the importance of endogenous selection. In the presence of unobserved heterogeneity, the matching of agents to contracts must be studied with care. If the outcome of the matching process is related to the unobserved heterogeneity variable (as one can expect), then the choice of the contract is endogenous. In particular, any empirical analysis taking contracts as given will be biased.

Contract theory, on the other hand, systematically emphasizes the distinction between adverse selection (whereby unobserved heterogeneity preexists the contractual relationship and constrains its form) and moral hazard (whereby behavior directly responds to the incentive structure created by the contract). As an illustration, consider the literature on automobile insurance contracts. The idea, here, is to test a standard prediction of the theory: everything equal, people who face contracts entailing more comprehensive coverage should exhibit a larger accident probability. Such a pattern, if observed, can however be given

\footnotetext{
${ }^{1}$ See the contribution by Attanasio and Rios-Rull in this volume.
} 
two different interpretations. One is the classical adverse selection effect à la Rothschild-Stiglitz: high risk agents, knowing they are more likely to have an accident, self-select by choosing contracts entailing a more comprehensive coverage. Alternatively, one can evoke moral hazard. If some agents, for exogenous reasons (say, picking up the insurance company located down the corner), end up facing a contract with only partial coverage, they will be highly motivated to adopt a more cautious behavior, which may result in lower accident rates. In practice, the distinction between adverse selection and moral hazard may be crucial, especially from a normative viewpoint. ${ }^{2}$ But it is also very difficult to implement empirically, especially on cross sectional data.

Most empirical papers relating contracts and behavior face, at least implicitly, a selection problem of this kind. Various strategies can be adopted to address it. Some papers explicitly recognize the problem, and merely test for the presence of asymmetric information without trying to be specific about its nature. In other cases, however, available data allow to disentangle selection and incentives. Such is the case, in particular, when the allocation of agents to contracts is exogenous, either because it results from explicit randomization, or because some "natural experiment" has modified the incentive structure without changing the composition of the population. In some cases, an explicit modelization of the economic and/or econometric structure at stake leads to simultaneous estimation of selection and incentives effects. Finally, a promising direction relies on the use of panel data; the underlying intuition being that the dynamics of behavior exhibit specific features under moral hazard.

\subsection{Testing for asymmetric information}

Several papers have recently been devoted to the empirical analysis of insurance contracts and insurees' behavior ${ }^{3}$. Following initial contributions by Dahlby (1983), Boyer and Dionne (1987) and Puelz and Snow (1994), a (non exhaustive) list includes Chiappori and Salanié (1997, 2000), Dionne, Gouriéroux and Vanasse (1999, 2001), Gouriéroux (1997), Richaudeau (1999), Cawley and Philipson (1999) and Bach (1999) ${ }^{4}$. In most cases, the nature of the test is straightforward: conditionally on all information that is available to the insurance company, is the choice of a particular contract correlated to risk, as proxied ex post by the occurrence of an accident?

This idea can be given a very simple illustration. Consider an automobile insurance context where insurees choose between two types of coverage (say, comprehensive versus liability only). Then they may or may not have an acci-

\footnotetext{
${ }^{2}$ One of the most debated issues regarding health insurance is the impact of deductible on consumption. It is a well established fact that, in cross sectional data, better coverage is correlated with higher expenditure levels. But the welfare implications are not straightforward. If incentives are the main explanation, deductibles or copayments are likely to be useful, since they reduce overconsumption. However, should selection be the main driving force, then limits on the coverage level can only reduce the insurance available to risk averse agents with no gain in terms of expenditure. The result is an unambiguous welfare loss.

${ }^{3}$ See Chiappori (2000) for a recent overview.

${ }^{4}$ A related reference is Toivanen and Cressy (1998), who consider credit contracts.
} 
dent during the subsequent period. The simplest representation of this framework relies on two probit equations. One describes the choice of a contract, and takes the form

$$
y_{i}=\mathbb{I}\left[X_{i} \beta+\varepsilon_{i}>0\right]
$$

where $y_{i}=1$ when the insuree chose the full coverage contract at the beginning of the period, 0 otherwise; here the $X_{i}$ are exogenous covariates that control for all the information available to the insurer, and $\beta$ is a vector of parameters to be estimated. The second equation relates to the occurrence of an accident:

$$
z_{i}=\mathbb{I}\left[X_{i} \gamma+\eta_{i}>0\right]
$$

where $z_{i}=1$ when the insuree had an accident during the period contract, 0 otherwise and $\gamma$ is a vector of parameters to be estimated. ${ }^{5}$ In this context, asymmetric information should result in a positive correlation between $y_{i}$ and $z_{i}$ conditional on $X_{i}$, which is equivalent to a positive correlation between $\varepsilon_{i}$ and $\eta_{i}$. This can be tested in a number of ways; for instance, Chiappori and Salanié (2000) propose two parametric tests and a non parametric test ${ }^{6}$. Interestingly enough, none of these tests can reject the null hypothesis of zero correlation (corresponding to the absence of asymmetric information).

These results are confirmed by most studies on automobile insurance ${ }^{7} ;$ sim- $^{-}$ ilarly, Cawley and Philipson (1997) find no evidence of asymmetric information in life insurance. However, Bach (1999), analyzing mortgage-related unemployment insurance contracts, finds that insurees who choose contracts with better (in her case earlier) coverage are more likely to become unemployed. Evidence of adverse selection has also been repeatedly found in annuity markets. Following earlier work by Friedman and Warshawsky (1990), Bruggiavini (1993) shows that, controlling for age and gender (the two variables used for pricing), annuity buyers have a longer life expectancy than the rest of the population. Recently, Finkelstein and Poterba (2000) have studied the annuity policies sold by a large UK insurance company since the early 1980s. Again, the systematic and significant relationships they find between ex-post mortality and some relevant characteristics of the policies suggest that adverse selection may play an important role in that market. For instance, individuals who buy more backloaded annuities are found to be longer-lived, whereas policies involving payment to

\footnotetext{
${ }^{5}$ An additional problem is that, typically, claims, not accidents, are observed. The decision to fill a claim is obviously influenced by many factors, including the form of the contract, which may induce spurious correlations. For that reason, most studies concentrate on accidents involving several vehicles and/or bodily injuries. See Dionne and Gagné (2001) for a careful investigation of these issues.

${ }^{6}$ One parametric test is based upon a computation of generalized residuals from independent estimations of the two probits, while the other requires a simultaneous estimation of the two probits using a general covariance matrix for the residuals. The nonparametric approach relies on the construction of "cells" of identical profiles, followed by a series of $\chi^{2}$ tests.

${ }^{7}$ One notable exception is the initial paper by Puelz and Snow (1994). However, subsequent studies strongly suggest that their result may be due to a misspecification of the model (see Chiappori and Salanié (2000) and Dionne, Gouriéroux and Vanasse (1999)).
} 
the estate in the event of an early death are prefered by customers with shorter life expectancy.

This empirical literature on asymmetric information in insurance suggests a few general insights. One is that asymmetric information may be an important issue in some insurance markets, but not in others. Ultimately, this is an empirical question, and the last word should be given to empirical analysis instead of theoretical speculations. From a more methodological perspective, the treatment of the information available to both the insuree and the insurer appears as a key issue. Correctly controlling for this information is a crucial but quite delicate task. It may be, for instance, that the linear forms used above are not flexible enough, in the sense that they omit relevant non linearities or cross effects $^{8}$. Should this be the case, then the resulting, omitted variable bias will result in a spurious correlation between contract choices and risk, that could mistakenly be interpreted as evidence of asymmetric information. A last conclusion is that static models may miss important dimensions of the problem. In automobile insurance, for instance, experience rating is known to play an important role. Insurers typically observe past driving records; these are highly informative on accident probabilities, and, as such, are used for pricing. Again, omitting past history in the probit regressions above will generate a bias towards overestimating the importance of asymmetric information. However, in the presence of unobserved heterogeneity, the introduction of variables reflecting past behavior raises complex endogeneity problems. In many cases, an explicit model of the dynamics of the relationship will be required.

\section{$2.2 \quad$ Experiments}

The most natural way to overcome selection problems is to make sure that the allocation of people to contracts is fully exogenous. Assume that different people are assigned to different contracts in a purely random way; then differences in observed behavior can safely be analyzed as responses to the different incentive structures at stake. Random assignment may be seen as an ideal situation, a kind of "first best" context for testing contract theory. Such situations, although infrequent, can however be found; their analysis generates some of the most interesting and robust conclusions of the literature.

The best example of a random experiment of this kind certainly is the celebrated Rand Health Insurance Experiment (HIE) ${ }^{9}$. Between November 1974 and February 1977, the HIE enrolled families in six sites in the US. Families participating in the experiment were randomly assigned to one of 14 different insurance plans, involving different coinsurance rates and different upper limits on annual out-of-pocket expenses. In addition, lump-sum payments were intro-

\footnotetext{
${ }^{8}$ Chiappori and Salanié argue that the use of simple, linear functional forms (such as logit or probit) should be restricted to homogenous populations, such as "young" drivers. An additional advantage of this approach is that it avoids the problems raised by experience rating.

${ }^{9}$ See Manning et al (1987).
} 
duced in order to guarantee that no family would lose by participating in the experiment.

The HIE has provided extremely valuable information about the sensitivity of the demand for health services to out-of-pocket expenditures under a number of different schemes. The use of medical services was found to respond to changes in the amount paid by the insuree. The largest decrease in the use of outpatient services occurs between a free plan and a plan involving a $25 \%$ copayment rate; larger rates did not significantly affect expenditures. The impact of the various features of the different plans could be estimated, as well as their interaction with such family characteristics as income or number of children. Also, it is possible, using the regressions results, to estimate "pure coinsurance elasticities", i.e. the elasticity of expenditures to coinsurance rates in the absence of ceilings on out-of-pocket expenses.

It is fair to say that the results of the HIE study have been extremely influential in the subsequent discussions on health plan reforms. The HIE will probably remain as one of the best empirical studies ever made in that field, a "Rolls-Royce" of empirical contract theory. However, quality comes at a cost. That of the HIE (130 million 1984 dollars) may not be totally prohibitive, but is high enough to severely hamper the repetition of such experiments in the future.

Fortunately, not only academics (or government agencies) are willing to run experiments of this kind. Knowledge about the incentive effects of contractual forms is valuable for firms as well; as a consequence, they may be eager to invest in acquiring such relevant information, in particular through experiments. In a recent contribution, Shearer (1999) studies the case of a tree-planting firm that randomly allocated workers to plant under piece rate and fixed wage contracts under a subset of planting conditions. Daily productivities were recorded for each worker, and are used to measure the percentage difference in average productivity under both types of payment. A simple ANOVA analysis suggest an incentive effect of piece wages of about $20 \%$. In addition, Shearer estimates a structural econometric model of worker behavior. This enables him to take into account non experimental data as well, to impose non linear restrictions on the ANOVA model, and finally to extend his conclusions to a larger set of planting conditions. The estimates appear to be very robust; Shearer finds a lower bound of $17 \%$ for the incentive effect.

Ausubel (1999) analyzes the market for bank credit cards. A substantial portion of bank credit card marketing today is done via direct-mailed preapproved solicitations; furthermore, several card issuers decide on the terms of the solicitations by conducting large-scale randomized trials. Ausubel uses the outcomes of such a trial to test for a standard prediction of adverse selection theory, namely that high risk agents are more willing to accept less favorable deals ${ }^{10}$. The trial is conducted by generating a mailing list of 600,000 customer names

\footnotetext{
${ }^{10}$ Technically, the market for credit card exhibits non exclusive contracts. In particular, the relevant theoretical reference is Stiglitz and Weiss (1981) rather than Rothschild and Stiglitz (1976) as in automobile insurance. Also, Ausubel focuses on testing for adverse selection, but he argues that moral hazard cannot explain his findings.
} 
and randomly assigning them among equal market cells. The market cells are mailed solicitations which vary in the introductory interest rate, in the duration of the introductory offer and in the post-introductory interest rate. Three tests can be conducted on these data. The first test relates to a "winner's curse" prediction: respondents should be worse borrowers than non respondents. Ausubel indeed finds that respondents have on average shorter credit histories, inferior credit rating, and are more borrowed-up than non respondents. Secondly, respondents to inferior offers (i.e., offers displaying a higher introductory interest rate, a shorter duration of the introductory period, or a higher post-introductory interest rate) are also worse borrowers on average, in the sense that they exhibit lower incomes, inferior credit records, lower balances on other credit cards and higher utilization rates of credit lines on other credit cards. Note, however, that these two tests involve characteristics that are observable by the bank and hence do not correspond to adverse selection in the usual sense. On the other hand, a third test looks for hidden information by checking whether, even after controlling for the observable characteristics of respondents to inferior offers, the latter still yield a customer pool which is more likely to default. The answer is an unambiguous yes, which provides very convincing evidence supporting the existence of adverse selection on the credit card market.

\subsection{Natural experiments}

Selection issues arise naturally in a cross-sectional context: if different people are involved in different contracts, the mechanism that allocates contracts to people deserves close scrutiny. Assume, however, that the same people successively face different contracts. Then selection is no longer a problem; in particular, any resulting change of behavior can safely be attributed to the variation of incentives, at least to the extent that no other significant factor has changed during the same period. This is the basic insight of natural experiments: incentive effects are easier to assess when they stem from some exogenous change in the incentive structure.

Changes in regulations constitute an obvious source of natural experiments. For instance, the automobile insurance regulation in Québec was modified in 1978 by the introduction of a "no fault" system, which in turn was deeply restructured in 1992. Dionne and Vanasse (1996) provide a careful investigation of the effects of these changes. They show in particular that the average accident frequency dropped significantly after strong incentives to increase prevention efforts were reinstored in 1992. They conclude that changes in agents' behavior, as triggered by new incentives, did have a significant effect on accident probabilities $^{11}$. Another illustration is provided by the study of tenancy reform in West Bengal by Banerjee, Gertler and Ghatak (2002). The reform, that took place in 1976, entitled tenants, upon registration with the Department of LandRevenue, to permanent and inheritable tenure on the land they sharecropped

\footnotetext{
${ }^{11}$ See Browne and Puelz (1999) for a similar study on US data.
} 
so long as they paid the landlord at least $25 \%$ of output as rent. The incentive impact of the reform is rather complex, since it changes the respective bargaining powers of the parties and the tenant's incentives to invest while reducing the set of incentive devices available for the landlord. To test for the impact of the reform, the authors use two methods. One is to use neighboring Bangladesh as a control; the fact that the reform was implemented in West Bengal but not in Bangladesh, the authors argue, was to a large extent due to an exogenous political shock. The second method compares changes in productivity across districts with different registration rates. Again, endogeneity might be a problem here; the authors carefully discuss this issue. They find that the reform significantly increased productivity.

Regulation is not the only cause of changes in incentive structures. Periodically, firms modify their incentive schemes, introduce new rewards, or restructure their wage schedules. Natural experiments of this kind have been repeatedly analyzed. To take only one example, Lazear (2000) uses data from a large auto glass company that changed its compensation structure from hourly wages to piece rates. He finds that, in accordance with the theoretical predictions, the productivity increases sharply, half of which can be attributed to existing workers producing more.

A first potential limitation of any work of this kind is that, strictly speaking, it establishes a simultaneity rather than a causality. What the studies by Dionne and Vanasse or Lazear show is that, on a given period, outcomes have changed significantly, and that this evolution immediately followed a structural change in incentives. But the two phenomena might stem from simultaneous and independent (or correlated) causes. The lower rate of accidents following the 1992 Québec reform may be due, say, to milder climatic conditions. Such a "coincidence" may be more or less plausible, but it is difficult to discard totally. A second and related problem is that the change in the incentive structure may well fail to be exogenous. This is particularly true for firms, which are supposed to adopt optimal contracts. If the switch from fixed wages to piece rates indicates that, for some reason, fixed wages were the best scheme before the reform but ceased to be by the time the reform was implemented, then a direct regression will provide biased estimates, at least to the extent that the factors affecting the efficiency of fixed wages had an impact on productivity Again, this type of explanation may be difficult to discard. ${ }^{12}$

The "coincidence" problem can be overcome when the experiment provides a "control" sample that is not affected by the change, so that the effects can be estimated in differences (or more precisely differences of differences). In two recent papers, Chiappori, Durand and Geoffard (1998) and Chiappori, Geoffard and Kyriazidou (2000) use such data on health insurance. Following a change in regulation in 1993, French health insurance companies modified the coverage offered by their contracts in a non uniform way. Some of them increased the level

\footnotetext{
${ }^{12}$ This remark illustrates a general phenomenon: if contracts are always optimal, then contract changes should always be taken as endogenous. In real life, however, (at least temporarily) inefficient contracts can hardly be assumed away - which, paradoxically, may simplify a lot the task of the econometrician!
} 
of deductible, while others did not. The tests use a panel of clients belonging to different companies, who were faced with different changes in coverage, and whose demand for health services is observed before and after the change in regulation. In order to concentrate upon those decisions that are essentially made by consumers themselves (as opposed to those partially induced by the physician), the authors study the number of physician visits, distinguishing between general practitioner office visits, general practitioner home visits and specialist visits. They find that the number of home visits significantly decreased for the "treatment" group (i.e., agents who experienced a change of coverage), but not for the "control" group (for which the coverage remained constant). They argue that this difference is unlikely to result from selection, since the two populations are employed by similar firms, they display similar characteristics, and participation to the health insurance scheme was mandatory.

A paper by Dionne and St-Michel (1991) provides another illustration of these ideas. They study the impact of a regulatory variation of the coinsurance level in the Québec public insurance plan on the demand for days of compensation. The main methodological contribution of the paper is to introduce a distinction between injuries, based on the type of diagnosis; it reflects the fact that it is much easier for a physician to detect a fracture than, say, lower back pain. In the first case, moral hazard (interpreted, in the ex post sense, as the tendency to cheat on the true severity of the accident) can only play a minor role, whereas it may be prevalent when the diagnosis is more difficult. In a sense, the easy diagnoses play the role of a control group, although in a specific way: they represent situations where the moral hazard problem does not exist. Theory predicts that the regulatory change will have more significant effects on the number of days of compensation for those cases where the diagnosis is more problematic. This prediction is clearly confirmed by empirical evidence. A more generous insurance coverage, resulting from an exogenous regulatory change, is found to increase the number of days on compensation, but only for the cases of difficult diagnoses. Note that the effect thus identified is ex post moral hazard. The reform is unlikely to have triggered significant changes in prevention; and, in any case, such changes would have affected all types of accidents.

Another natural experiment based on reforms of public programs is studied by Fortin et al. (1994), who examine how the Canadian Worker's Compensation (WC) and the Unemployment Insurance (UI) programs interact to influence the duration of workplace accidents. They show that an increase in the generosity of WC in Québec leads to an increase in the duration of accidents. In addition, a reduction in the generosity of Unemployment Insurance is, as in Dionne and St-Michel, associated with an increase in the duration of accidents that are difficult to diagnose. The underlying intuition is that worker's compensation can be used as a substitute to unemployment insurance. When a worker goes back to the labor market, he may be unemployed and entitled to UI payments for a certain period. Whenever worker's compensation is more generous than unemployment insurance, there will be strong incentives to delay the return to the market. In particular, the authors show that the hazard of leaving $\mathrm{WC}$ is $27 \%$ lower when an accident occurs at the end of the construction season, when 
unemployment is seasonally maximum ${ }^{13}$.

Finally, an interesting situation is when the changes in the incentive structure are random but endogenous. Take the example of mutual fund managers, as studied by Chevalier and Ellison (1997). The basic assumption of the paper is that fund companies have an incentive to increase the inflow of investments. That, in turn, depends on the fund's performance in an implicit contract between fund companies and their customers. The authors estimate the shape of the flow-performance relationship for a sample of funds observed over the 198292 period, and find that it is highly non linear. Such a nonlinear shape, in turn, creates incentives for fund managers to alter the riskiness of their portfolios, and these incentives vary with time and past performance. Examining portfolio holdings, the authors find that risk levels are changed toward the end of the year in a manner consistent with these incentives. For instance, the flow performance is convex for funds that are ahead of the market; and as expected, these tend to gamble so as to increase their expected inflow of investment ${ }^{14}$. In a similar vein, Oyer (1998) remarks that compensation contracts for salespersons and executives are typically non linear in firm revenues, which creates incentives for these agents to manipulate prices, vary effort and influence the timing of customer purchases. Using an extensive data set (gathering firm revenue and cost of goods sold for 31,936 quarterly observations covering 981 manufacturers), Oyer finds evidence of business seasonality patterns that fully support the theoretical predictions.

\subsection{Explicit modelling}

Econometric tools In the absence of (natural) experiments, the endogenous matching problem is pervasive. Adequate theoretical tools may however allow to tackle it in a satisfactory way. From the econometric perspective, much attention has been devoted to exogeneity tests, which find a natural application in our context. An illustration is provided by Laffont and Matoussi (1995), who study a model of sharecropping with moral hazard. The main prediction of this class of models is that production increases with the share of the product kept by the tenant. Laffont-Matoussi use data collected in 1986 on contracts and production in a Tunisian village to test that sharecropping indeed reduces production. To do this, they estimate augmented Cobb-Douglas production functions, adding contract dummy variables as explanatory variables. They find that moving from a sharecropping contract to a rental contract increases production by $50 \%$ on average. However, longer-term sharecropping relationships, which allow for delayed retaliation, tend to be much more efficient, as one would expect from the repeated moral hazard literature in a context of missing credit markets (see Chiappori-Macho-Rey-Salanié (1994)).

\footnotetext{
${ }^{13}$ See also Fortin and Lanoie (1992), Bolduc et al. (forthcoming), and the survey by Fortin and Lanoie (1998).

${ }^{14}$ Chevalier and Ellison (1999) extend this approach to study the impact of career concerns on the investment decisions of mutual fund managers. For another, recent work on the incentive impact of managerial contracts, see Lemmon, Schallheim and Zender (2000).
} 
As presented above, the Laffont-Matoussi approach seems very sensitive to the criticism of selection bias: if they find higher production in plots with rental contracts, it may simply be that rental contracts are more often adopted for more fertile plots. Their answer to this criticism is to test for exogeneity of the contract type variables in production functions. This they do, and they do not reject exogeneity, which validates their approach. One problem with exogeneity tests is that they may not be very powerful. As we will see, another solution to the selection bias problem is to use instruments. In fact, the exogeneity test used by Laffont-Matoussi assumes that some variables (such that the tenant's age, his wealth and working capital) are valid instruments for the contract variables in the production function.

Structural models of regulation under adverse selection Often, however, identification requires a full-grown structural model. Wolak (1994) pioneered the estimation of structural models with adverse selection. His paper is set within the context of the regulator-utility relationship for California water companies. However, it is simpler to present it for a price discriminating monopoly (the principal) facing consumers (agents) with an unknown taste $\theta$ for the good. Let $X$ be the vector of exogenous variables that are observed by both parties and by the econometrician, $\alpha$ be the vector of parameters we want to estimate, and let $q$ be the quantity traded as per the contract. The observational status of $\theta$ depends on our assumptions. First consider model $S$ (for symmetric information), in which both Principal and Agent observe $\theta$. Then we obtain by maximizing the total surplus ${ }^{15}$ a likelihood function $l^{S}(q, X, \alpha ; \theta)$. Note that this is conditional on $\theta$.

Now consider the more interesting model $A$ (for asymmetric information) in which only the Agent knows $\theta$ and the Principal has a prior given by a probability distribution function $f$ and a cumulative distribution function $F$. In that case, we know from the theoretical literature that under the appropriate hazard rate condition, the solution is given by maximizing the virtual surplus, which generates a likelihood function

$$
l^{A}(q, X, \alpha ; \theta,(1-F(\theta)) / f(\theta))
$$

Note that the latter is conditional both on $\theta$ and on $(1-F(\theta)) / f(\theta)$.

Assume that we have data on $n$ relationships between Principals and Agents that are identical except for the exogenous variables $X$, so that our sample is $\left(q_{i}, X_{i}\right)_{i=1}^{n}$. The difficulty here is that we do not know $\theta$ or $f$, even in model $S$ in which both parties observe $\theta$. In econometric terms, $\theta$ is an unobserved heterogeneity parameter and we must integrate over it. To do this, we must find a functional form for $f$ that is flexible enough, given that we have very little idea of what the Principal's prior may look like. Let $\left(f_{\gamma}\right)$ be such a parameterized family.

\footnotetext{
${ }^{15}$ Assuming that utilities are quasi linear.
} 
We can now estimate all parameters of model $S$ by maximizing over $\alpha$ and $\gamma$ the $\log$-likelihood

$$
\sum_{i=1}^{n} \log \int l^{S}\left(q_{i}, X_{i}, \alpha ; \theta\right) f_{\gamma}(\theta) d \theta
$$

To estimate model $A$, we must first integrate $f_{\gamma}$ to get $F_{\gamma}$; then we maximize

$$
\sum_{i=1}^{n} \log \int l^{A}\left(q_{i}, X_{i}, \alpha ; \theta, \frac{1-F_{\gamma}(\theta)}{f_{\gamma}(\theta)}\right) f_{\gamma}(\theta) d \theta
$$

These log-likelihood functions are obviously highly nonlinear and also require a numerical integration in both models; however, modern computers make it quite feasible to maximize them.

As pointed out before, Wolak (1994) introduced this approach to study the regulation of water utilities in California in the 80 s. He found that non-nested tests à la Vuong (1989) favour model $A$ over model $S$, indicating that asymmetric information is relevant in this regulation problem. Wolak also noted that using model $S$ instead of model $A$ may lead the analyst to conclude wrongly that returns are increasing, whereas they are estimated to be constant in model $A$. Finally, he was able to evaluate the underproduction that is characteristic of adverse selection models to about $10 \%$ in the middle of the $\theta$ range.

One difficulty with Wolak's method is that the econometrician only observes the conditional distribution of $q$ given $X$; thus identification of the preferred model heavily relies on functional form assumptions. Without them, it is easy to find examples in which model $S$ with parameters $(\alpha, F)$ yields exactly the same likelihood function as model $A$ with parameters $\left(\alpha^{\prime}, F^{\prime}\right)$, so that there is no way to discriminate between these two models on the basis of data. Of course, this problem is not specific to Wolak's model; it is just the usual identification problem in structural models, with the new twist that the parameter $F$ is really infinite-dimensional ${ }^{16}$.

Ivaldi and Martimort (1994) have used a similar approach in a model that has both market power and asymmetric information. They study competition through supply schedules in an oligopoly where two suppliers of differentiated goods do not know the consumers' valuations for the two goods. They model this situation as a multiprincipals game where the suppliers are the principals and the consumers are the agents. Assuming supply schedules to be quadratic, they derive the perfect bayesian equilibrium in supply schedules and the corresponding segmentation of the market according to the valuations of consumers for the two goods.

Ivaldi and Martimort apply this theoretical model to study energy supply to the French dairy industry. The first supplier is the public sector monopoly on

\footnotetext{
${ }^{16}$ Wolak also assumes that the regulator maximizes social welfare. Timmins (2000) relaxes this assumption and estimates the relative weights of consumers' surplus and of firms' profits in the regulator's objective function. Gagnepain and Ivaldi (2001) take the existing regulatory framework as given; they estimate the structural parameters of supply and demand and use them to simulate the optimal contracts.
} 
gas and electricity, EDF-GDF. The second supplier consists of oil firms, who are assumed to act as a cartel. Oil firms maximize profit, but EDF-GDF maximizes social welfare. The authors use pseudo-maximum likelihood (Gouriéroux, Monfort and Trognon (1984)) to estimate the structural equations derived from their theoretical model. They find that the estimated variance of suppliers' priors on the valuations of consumers is significantly positive, so that there is evidence of asymmetric information in this market. Obviously, our remark on identification in Wolak's model also applies here. ${ }^{17}$

Structural models involving moral hazard and selection Structural models can be used in a more specific way to disentangle selection from incentive effects. Paarsch and Shearer (2000) analyze data from a tree planting firm, where some workers receive a piece rate whereas others are paid a fixed wage. In their model, the decision to adopt a piece rate or a fixed wage is modelled as resulting from the observation of the planting conditions by the firm. The endogeneity problem arises from the fact that neither the planting conditions nor the individual-specific cost of effort are observed by the econometrician. According to the structural model developed in the paper, fixed wages are efficient under poor planting conditions and for less productive employees, whereas piece rates work well in more favorable contexts. A direct comparison of observed productivities under each type of contract thus is biased, because the estimated difference results partly from the incentive effect of piece rates, and partly from the selection effect. Hence observed discrepancies in productivity provide an upper bound of the incentive effect. Conversely, differences in real earnings provide a lower bound for the incentive effect. This simple idea can be taken to the data quite easily; the authors find an upper (resp. lower) bound of $60 \%$ (resp. 8\%). Finally, a parametric version of the structural model is estimated. The authors conclude that about half of the difference in productivity is due to incentive effects and half to selection. Interestingly enough, these non-experimental findings are fully compatible with the experimental results in Shearer $(1999)^{18}$.

A related approach is adopted by Cardon and Hendel (2001), who consider employer-provided health insurance. As argued above, a contract that involves a larger copayment rate is likely to correspond to smaller health expenditures, either because of the incentive impact of the copayment rate or because high risk agents self-select by choosing contracts entailing more coverage. The main identifying assumption used by Cardon and Hendel is that agents do not choose their employer on the basis of the health insurance coverage. A consequence is that while the allocation of individuals among the various options of a given plan typically reflects adverse selection, the differences in behavior across plans must be due to incentive effects. Again, a structural model is needed to disentangle

\footnotetext{
${ }^{17}$ See also Lavergne and Thomas (2000)

${ }^{18}$ Paarsch and Shearer (1999) use a similar model, where the firm, having observed the planting conditions, chooses a specific piece rate. Again, the structural model allows to take into account the endogeneity of the rate.
} 
the two effects; the authors find that selection effects are negligible, whereas incentives matter ${ }^{19}$.

\subsection{Using behavioral dynamics}

If selection and moral hazard are difficult to disentangle in a static context, a natural response is to turn to dynamic data. ${ }^{20}$ Adverse selection and moral hazard indeed induce different behavioral dynamics, which provides a new source for identification. An illustration of this line of research is provided by a recent work by Chiappori, Abbring, Heckman and Pinquet (2001). They consider a French data base provided by an automobile insurer. A particular feature of automobile insurance in France is that pricing relies on experience rating (i.e., the premium associated to any particular contract depends, among other things, on the past history of the relationship) but the particular form experience rating may take is strongly regulated. All companies must apply the same "bonus/malus" system, according to which the premium is decomposed as the product of a "basis" premium, freely set by the insurer but independent of past history, and a bonus coefficient, the dynamics of which is imposed by law. Specifically, the coefficient is decreased by a factor $\mu<1$ after each year without an accident but increased by a factor $\lambda>1$ after each year with an accident ${ }^{21}$. The authors show that this scheme has a very general property, namely that each accident increases the marginal cost of (future) accidents. Under moral hazard, any accident thus increases prevention efforts and reduces accident probability. The conclusion is that for any given individual, moral hazard induces a negative contagion phenomenon: the occurrence of an accident in the past reduces accident probability in the future. The tricky part, however, is that this prediction holds only conditional on individual characteristics, whether observable or unobservable. As is well known, unobserved heterogeneity induces an opposite, positive contagion mechanism: past accidents are typical of bad drivers, hence are a good predictor of a higher accident rate in the future. The problem thus is to control for unobserved heterogeneity. This problem is fairly similar to an old issue of the empirical literature on dynamic data, namely the distinction between pure heterogeneity and state dependence. The authors show that non parametric identification can actually be achieved under mild identifying restrictions, even when the history available to the econometrician about each driver only consists of the number of years of presence and the total number of accidents during this period. Using a proportional hazard duration model on French data, they cannot reject the null of no moral hazard.

\footnotetext{
${ }^{19}$ Other references include, among others, Holly et al (1998) and Ferrall and Shearer (1999).

${ }^{20} \mathrm{~A}$ different but related idea is that the use of panel data allows to control for unobserved heterogeneity and selection issues in a much more satisfactory way than in cross-sectional analysis. See for instance MacLeod and Parent (1999).

${ }^{21}$ Currently, $\mu=.95$ and $\lambda=1.25$. In addition, the coefficient at any time is capped anfd floored (at 3.5 and .5 respectively). Note that the strict regulation avoids selection problems, since the insuree cannot choose between menus involving different bonus/malus coefficients, as is often the case in other countries.
} 


\section{Are contracts optimal?}

We now turn to tests of contract optimality. The papers we are going to survey all focus on the same question: do observed contracts have the properties predicted by contract theory? There is a sense in which the answer is always positive: given any contract, a theorist with enough ingenuity may be able to build an ad hoc theory that "explains" it. The operative word here is "ad hoc". Clearly, there is no precise definition of what constitutes an ad hoc assumption, but there may be accepted standards. So we can rephrase the optimality question thus: do the properties of observed contracts correspond to those that the currently standard models of contract theory predict? This new formulation makes it clear that a negative answer may only be temporary, as better models with new predictions are developed (ideally, in response to such rejections of currently standard models).

\subsection{Static, complete contracts}

\subsubsection{Managerial Pay}

The standard model of moral hazard implies that managers' pay should be sensitive to their firms' performance. The "pay-performance sensitivity" has been estimated by many papers (for a recent survey of the evidence, see Murphy (1999)). The seminal contribution is that of Jensen-Murphy (1990); using data on CEOs of US firms from 1969 to 1983, they obtained what seemed to be very low estimates of the elasticity of executive compensation to firm performance. Their oft-quoted result was that when the firm's value increases by $\$ 1,000$, the (mean) manager's wealth only increases by $\$ 3.25$.

The early reaction to Jensen and Murphy's result was that they indicated inefficiently low incentives for top management (see for instance Rosen (1992)). However, Haubrich (1994) showed that even fairly low levels of manager's risk aversion (such as a relative index of risk aversion of about 5) were consistent with this empirical result. The intuition is that for large companies, changes in firm value can be very large and imply large swings in CEO wealth even for such lowish pay-performance sensitivity levels. Moreover, more recent estimates point to much higher elasticities. Thus, Hall-Liebman (1998) use a more recent dataset (1980 to 1994). They show that the spectacular increase in the stock options component of managers' pay has made their pay much more sensitive to firm performance. Their mean (resp. median) estimate of the change in CEO wealth (salary, bonus, and the change in value of stocks and stock options) linked to a $\$ 1,000$ increase in firm value indeed is about $\$ 25$ (resp $\$ 5.3$ ). Much of it is due to the change in value of stocks and stock options.

Another testable implication of the moral hazard model is that pay-performance sensitivity should be inversely related to the variance of the measure of performance used (typically firm value for managers). Aggarwal-Samwick (1999) show that, indeed, CEO pay is much less sensitive to performance for firms whose 
stock returns are less volatile $\mathrm{e}^{22}$. This result, however, may itself be sensitive to the choice of covariates. ${ }^{23}$ This illustrates a problem frequently encountered by this literature. Theory predicts the form of optimal contracts within simplified models, where comparative statics are easy to work out (one can change the level of uncertainty within a moral hazard model by varying one parameter). Taking such predictions to data typically requires some very strong "everything equal" qualification. In practice, firms differ by the uncertainty they face, but also by their size, market share, relationship to the clients, technology, internal organization and others - all of which moreover may be correlated in various ways. In this context, sorting out one particular type of causality is a difficult task indeed.

Other models relate the use of a particular form of compensation to the characteristics of the task to be performed. Using various data sets, MacLeod and Parent (1999) find, for instance, that jobs using high power incentives are associated with more autonomy on the job, and that a high local rate of unemployment results in less discretion in pay or promotion, confirming standard conclusions of incomplete contract theory.

Finally, one empirical puzzle in this literature is that firms do not seem to use relative performance evaluation of managers very much ${ }^{24}$. The theory indeed predicts that managers should not be paid for performance that is due to "observable luck" such as a favourable industry-wide exchange rate shock or a change in input prices. Bertrand and Mullainathan (2001) revisit this issue of "pay for luck"; they find that manager pay in fact reacts about as much to performance changes that are predictable from observable luck measures as to unpredictable changes in performance. This clearly contradicts the theoretical prediction. However, Bertrand and Mullainathan also find that better governed firms (such as those with large shareholders) give less pay for luck, as one would expect.

\subsubsection{Sharecropping}

Many papers have tested the moral hazard model of sharecropping, and we will only quote a few recent examples ${ }^{25}$. Ackerberg-Botticini (forthcoming) regress the type of contract (rental or sharecropping) on crop riskiness and tenant's wealth. As explained above, theory predicts that more risky crops are more likely to be grown under sharecropping contracts. If wealth is taken to be a proxy for risk-aversion, we would also expect that richer (and presumably less risk-averse) tenants are more likely to be under a rental contract. Now wealth is only an imperfect proxy for risk-aversion, and as explained earlier, the unobserved component of risk-aversion is likely to be correlated with crop riskiness.

\footnotetext{
${ }^{22}$ Aggarwal and Samwick use panel data and include fixed CEO effects, which allows them to control for CEO risk aversion.

${ }^{23}$ For instance, Core and Guay (2000) find that the sign of the relationship is reversed when controlling for firm size.

${ }^{24}$ Although Gibbons and Murphy (1990) argue that they do.

${ }^{25}$ Other recent works include, in particular, a series of papers by Allen and Lueck (1992, 1993, 1998, 1999).
} 
This implies that the error in the contract choice equation is correlated with one of the explanatory variables, and the estimators of such a naive regression are biased. To remedy this endogenous matching problem, Ackerberg and Botticini instrument the crop riskiness variable, using geographical variables as instruments. They find that the results are more compatible with theory than a naive regression would suggest. Moreover, the implicit bias in the naive estimators goes in the direction implied by a matching of more risk-averse tenants with less risky crops: it leads to overestimating the effect of crop risk and underestimating the effect of wealth. ${ }^{26}$

Laffont-Matoussi (1995) test a different variant of the moral hazard sharecropping model. In their story, tenants are risk-neutral; but they are facing financial constraints that limit how much risk they may take. This model predicts that tenants with less working capital tend to work under sharecropping or even wage contracts. They find that their Tunisian data supports this prediction.

In either of these variants, the theory used is drastically simplified. Empirical work must often extend the theory to take into account features of real-world applications. Dubois (1999) makes a step in that direction by taking into account landlords' concerns that tenant effort may exhaust the soil and reduce future land fertility and hence future profits. This is a problem because contracts are incomplete: they cannot be made contingent on land fertility. Moreover, many contracts extend over only one season and so long-term contracts are not feasible. Then sharecropping may be optimal even with risk neutral tenants, as it improves future land fertility by reducing tenant effort. This "extended model" of sharecropping has some predictions that differentiate it from the "canonical model" of Stiglitz (1974) and that seem to fit Dubois's Philippines dataset better. For instance, the data shows that incentives are higher-powered for more valuable plots of land. This is incompatible with most versions of the canonical model; on the other hand, it is quite possible under the extended model. Moreover, observed incentives are lower-powered for crops such as corn that tend to exhaust the soil, as the extended model predicts.

The theory also predicts that a technological shock that makes the effort of the tenant less crucial should increase the share of the landlord at the optimal contract. Hanssen (2001) argues that this is exactly what happened in the movie industry with the coming of sound in 1927. When films were silent, the exhibitor was expected to provide musical background and other live acts. With sound films, all of this was incorporated in the movie itself, making the receipts less sensitive to the exhibitor's effort. Hanssen shows that as we would expect, contracts between film companies and exhibitors rapidly moved from flat-fee rentals to the revenue-sharing agreements that now dominate the industry.

Finally, when long-term contracts are available, they are effective in providing incentives for non-contractible investment. If incentive provision is costly

\footnotetext{
${ }^{26}$ An alternative strategy used by Dubois $(2000 \mathrm{a}, \mathrm{b})$ is to independently estimate individual risk aversion (as a function of the available covariates) from a panel data on consumptions (in the line of the consumption smoothing literature), then include the estimated parameter of risk aversion within the explanatory variables for the contract choice equation.
} 
because of information rents, long-term contracts will be employed only when maintenance benefits are large enough. This idea is exploited by Bandiera (1998) in her study of agricultural contracts in 19th century Sicily. She finds that longterm contracts were indeed used for crops requiring higher maintenance efforts.

There are still some features of sharecropping contracts that are harder to explain. One of them is that the share of output that goes to the tenant is not as responsive to economic fundamentals as theory predicts it should be. Young and Burke (2001) show that in their sample of Illinois farms, almost all contracts have the same tenant share for all types of crops, and this share is one-half for $80 \%$ of the contracts. They argue that such inflexible terms are due to local custom: while shares do vary across regions, they are almost constant within regions. Young and Burke put this down to fairness concerns.

\subsection{Multitasking}

Both the managerial pay and the sharecropping literature test traditional versions of the moral hazard model; but more recent variants have also been tested. Slade (1996) tests the multitask agency model of Holmstrom-Milgrom (1991) on contracts between oil firms and their service stations in the Vancouver area. Service stations do not only deliver gasoline; they may also act as convenience stores and/or repair cars. In multitask models, the form of the optimal contract crucially depends on complementarity patterns between tasks: incentives should be lower-powered when tasks are more complementary. Slade argues that the convenience store task is likely to be more complementary to the gasoline task than the repairs task. Thus the theory predicts that service stations that also do repairs should face higher-powered incentives than those that run convenience stores. Slade tests this prediction by running Probits for contract type: service station operators may be lessee dealers (with high-powered incentives) or commissioned agents (with low-powered incentives). She finds that as predicted by the theory, doing repairs increases the probability of running a lessee dealership, while having a convenience store reduces it.

\subsection{Incomplete contracts/transaction costs}

The formal literature on incomplete contracts is still rather young, and to the best of our knowledge, it has not been submitted yet to econometric testing ${ }^{27}$. On the other hand, a number of papers have tested the main intuitions from the transactions costs literature as developed by Williamson $(1975,1985,1996)$. We will only give a few examples; the reader can refer to more detailed surveys such as Shelanski-Klein (1995).

Perhaps the best known result from the transactions costs literature, following Williamson, is that when relationship-specific investments matter more, contracts will have a longer duration (so as to avoid hold-up problems). This has been tested by Joskow (1987). He studies the relationship between coal suppliers and electric plants that burn coal in the US in 1979.

\footnotetext{
${ }^{27}$ We will discuss a descriptive study of Kaplan-Strömberg (1999) below.
} 
Williamson distinguishes four types of specificity. Joskow uses three of them to construct testable predictions:

- site specificity: some electric plants are "mine-mouth", i.e. located close to the coal mine that supplies them.

- physical asset specificity: electric plants are designed to burn a specific type of coal (but not necessarily from a specific supplier). Joskow argues that this consideration matters most in the West, less in the Midwest, and least in the East.

- dedicated asset specificity: this holds when large annual quantities are contracted for.

Thus transaction cost theory predicts that contracts should have longer duration when they involve mine-mouth plants, when the firms are in the West, and when large annual quantities are contracted for. Joskow runs a simple regression of contract duration on the three specificity variables and finds that all three hypotheses are robustly validated by the data.

Crocker-Masten (1988) also test whether the determinants of contract duration conform to what transactions costs theory predicts, with one interesting twist. This goes back to the difficulty for the analyst to know whether actual contracts optimally maintain incentives for efficient adaptation, while minimizing need for costly enforcement. Crocker and Masten argue that sometimes there is external interference from courts or government which makes contract terms deviate from the optimal trade-off in predictable ways, and this can be used by the econometrician. They use the example of natural gas, where wellhead regulation at times imposed price ceilings at the producer level. When such a price ceiling is binding, contracts should stipulate higher damages or take-or-pay rates so as to protect producers. Then the contract is less efficient, and the contract duration will be shorter-unless the seller fears that the next renegotiation will lead to much lower prices. Crocker and Masten indeed find that when the price ceiling is much lower than the notional price (estimated as the latent variable in a Probit model), contracts have a shorter duration. This effect is highly significant and matters a lot: price regulation may have shortened contract duration by half.

Crocker-Reynolds (1993) look at the determinants of the degree of contract incompleteness itself. They argue that this results from a trade off between the ex ante costs of crafting more detailed arrangements and the ex post costs of inefficiencies. Since the former increase with uncertainty and complexity and the latter increase with the likelihood of opportunistic behavior, one expects that contracts will be less complete when the environment is more uncertain and complex and when opportunistic behavior is less likely. Crocker and Reynolds test these predictions on a sample of US Air Force procurement contracts. They run an ordered probit for the type of the contract on variables that proxy for uncertainty and the reputation of the supplier for opportunistic behavior. Their results support the theoretical prediction. 
Transactions costs theory also predicts that when quasi-rents are large, sometimes even long-term contracts won't suffice and vertical integration will take place. A number of papers have tested this prediction and generally found good support for it. An early example is Monteverde-Teece (1982). They looked at the "make or buy" decision in the automobile industry: should components be produced in-house or should they be obtained from outside suppliers? They argued that the answer depends on whether making a particular component involves much or little engineering specific knowledge. Then they ran a Probit of the make-or-buy decision on a set of variables that included a measure of engineering specific knowledge provided to them by an independent engineer. They found that as predicted by the theory, components tend to be made in-house when they involve more specific knowledge.

Some less obvious results from transactions costs theory have also been tested. Thus Crocker-Masten (1991) look at the provisions for adjusting prices during the lifetime of contracts. Some contracts rely on "redetermination provisions": price adjustment is predetermined through a more or less contingent price adjustment formula. Others emphasize renegotiation provisions, which more or less structure the process of renegotiating prices. Crocker and Masten argue that renegotiations provisions are more useful when the environment is more uncertain or the contract has a longer duration. To test this, they examine a 1982 sample of natural gas contracts in the US. The observed price adjustment provisions are very diverse, but a Probit model for renegotiation vs redetermination validates the predictions of the theory.

Transactions costs theory has also been tested against other theories. For instance, Hubbard-Weiner (1991) use natural gas contracts in the US in the 50s to examine whether considerations of market power or of efficient contracting matter most. Market power is often invoked in this market, because switching contracting parties is difficult and thus there is an element of bilateral monopoly. A linear regression for contract prices (paid by the pipeline to the gas producer) indeed appears to show some evidence for pipeline monopsony power: prices are higher in regions with more pipelines. However, Hubbard and Weiner show that this is due to a spurious correlation: growing markets have more pipelines, but they also exhibit larger quasi-rents. The existence of these quasi-rents motivates the use of a most-favoured-nation clause according to which a pipeline that has a contract with producer $\mathrm{A}$ and signs a new contract with producer $\mathrm{B}$ at a higher price must grant that new price to producer A. Because the mostfavoured-nation clause tends to be associated with higher prices, this generates the positive correlation between prices and the number of pipelines. That correlation thus appears to be due to efficient contracting considerations and not to market power on either side.

Most of the empirical tests of transactions costs theory have been implemented on data from relatively thin markets, where quasi-rents are large. An interesting question is whether these intuitions extend to thicker markets. This has been studied by Hubbard (1999) for the trucking industry. This is an industry in which assets are not very specific, even less so when local markets are thick. Still, there is some variation on how thick local markets are, and 
transactions cost theory then predicts that spot arrangements should be more likely when the local market is thicker. Hubbard runs an ordered logit on the various contractual forms in the industry that confirms this prediction.

It is fair to say that most of the empirical literature has been supportive of the basic ideas of transactions costs theory. Nevertheless, it is hard to feel completely satisfied with the methodology of these studies. One first problem is a consequence of the somewhat vague character of some of the concepts in the theory: because quasi-rents or uncertainty are such broad categories, it is very difficult to find good proxies for them. Besides, it is not always clear what the observability/verifiability status of these variables is. Consider uncertainty for instance; in this literature, it is often proxied by the volatility of a price index. But this is certainly verifiable information, so one still has to explain why the contract is not made contingent on the value of that price index.

A second problem with this literature is that it usually does not control for the possible endogeneity of right-hand side variables. Consider for instance Joskow's 1987 study described above. One of the right-hand side variables is a dummy variable for a mine-mouth location. But we are not given any evidence on the determinants of the decision to site a plant mine-mouth; and that may certainly depend on unobserved factors that also influence contract duration, making the mine-mouth variable endogenous in the regression of contract duration. Because Joskow does not attempt to correct for endogeneity or to test for it, the estimates may be biased. A related point is that Joskow does not condition on the fact that these firms are not vertically integrated ${ }^{28}$, whereas the decision to not vertically integrate again may be correlated with contract duration. Clearly, these two points exemplify the endogenous matching problem that we mentioned repeatedly: regressions of contract variables on characteristics of the parties are fraught with selection bias and endogeneity problems.

Finally, what does this tell us about the more recent theory of incomplete contracts, as exposited in Hart's (1995) book? Since many of the underlying ideas started with transactions costs theory, one might think that the relative empirical success of the older theory somehow validates the newer one. However, this would certainly be premature, as argued by Whinston (2000) for theories of vertical integration. One first point is that because incomplete contracts theory is more formalized, it has a much richer set of predictions than transactions costs theory does. By implication, it exposes itself more to empirical refutation. A second point is that testing incomplete contracts theory is bound to be a much more demanding task. While we have argued that transactions costs theory relies on quasi-rents that may be difficult to proxy properly, the situation is even worse for incomplete contracts theory, as its predictions rather precisely depend on how the marginal returns to non-contractible investments are distributed among the parties. Measuring these marginal returns reliably enough to test the predictions of the theory will require much more highly detailed information

\footnotetext{
${ }^{28}$ In a separate paper, Joskow (1985) explores the determinants of vertical integration for this same sample; but what we would want is a joint modelling of contract duration and the decision to vertically integrate.
} 
on contracting environments than is usually present in our datasets ${ }^{29}$.

Of course, one may forgo econometrics for the moment and take a more descriptive look at the data. A first attempt to do this is the work by KaplanStrömberg (1999), who analyze a large number of venture capital contracts. The authors argue that venture capitalists (VCs) are real world entities who most closely approximate the investors of the theory; hence, relating theoretical predictions to real-life VC contracts will provide precious insights about the relevance of theory. Indeed, some of their findings tend to support standard predictions of the incomplete contract literature. Separate allocation of cash-flow and control rights is a standard feature of VC contracts. The allocation of rights is contingent on observed measures of financial and non financial performance, especially at early stages of the relationship. Existing contracts are consistent with a basic prediction of the theory, namely, that control should be left to the manager in case of success (then the VC keeps cash-flow rights only), whereas it shifts to the venture capitalist when the firm's performance is poor. Finally, the importance of non-compete and vesting provisions suggests that imperfect commitment and hold-up problems are indeed an important aspect of VC contracts. However, some theories appear to fare less well than others. "Stealing" theories à la Hart and Moore (1998) or Gale and Hellwig (1982), for instance, rely on the impossibility of making contracts contingent on profits (or other measures of financial performance), an assumption that is not supported by the data. Finally, several problems are left open by the empirical investigation. For instance, existing theories cannot explain why we observe in these contracts that control rights are allocated across a number of dimensions such as voting rights, board rights, or liquidation rights. Similarly, the variety and the complexity of the financial tools used to allocate rights - convertible securities (with specific strikes), common and preferred stocks,...-go well beyond the simple settings (typically, debt versus equity) considered so far.

Finally, some recent studies usefully remind us that there may be more to incomplete contracting than transactions costs theory or the more recent approach. Banerjee and Duflo (1999) focus on the Indian customized software industry, which writes specialized software for (usually) foreign clients. In this industry, the product is very difficult to describe ex ante; the client writes a vague description of what he wants, software firms bid by announcing a price and a time schedule, and the client chooses who he will contract with. Much of the process of describing the functions of the software is interactive and takes place after the contract is signed. Therefore the contracts are highly incomplete and cost overruns are frequent: three-quarters of the contracts have cost overruns, of $25 \%$ of planned costs on average. Because the initial description of the software is so vague, it would be impossible for a court to decide in what proportions the overruns are due to the firm or to the client. In practice, the contracts are often renegotiated in case of cost overruns, so as to increase the price the software firm is paid. Banerjee and Duflo find that the client is more generous in these renegotiations when he faces an older firm, especially if he

${ }^{29}$ Whinston (2001) and Baker and Hubbard (2001) also discuss this issue. 
has already contracted with that firm in the past. Banerjee and Duflo put it down to reputation effects: they argue that older firms have shown in the past that they were reliable, all the more so if the client has already dealt with them. They show that alternative explanations fit the data less well ${ }^{30}$.

McMillan and Woodruff (1999) use a survey of private firms in Vietnam to investigate the determinants of trade credit. Vietnam does not have a reliable legal system, so trust matters a great deal. McMillan and Woodruff indeed find that a firm tends to grant more trade credit to its customers when these have no alternative supplier, when the supplier has more information about the customer's reliability, and when the supplier belongs to a business or social network that makes information available and/or makes it easier to enforce sanctions.

Baker and Hubbard (2000a) investigate the impact on asset ownership of technological changes that modify the contractibility of actions. They consider the U.S. trucking industry, where the introduction, in the late 1980s, of on-board computers (OBC) allowed contracts to be made contingent on various operating parameters of trucks (speed, etc.). Because of the exogenous enlargement of the space of feasible contracts, suboptimal behavior becomes monitorable, and the need for powerful incentive schemes (such as ownership by drivers) is reduced. Using a survey of the US trucking fleet, they actually find that OBC adoption leads to less driver ownership. All OBCs are not equal, however: some improve the monitoring of drivers and others improve the coordination of the fleets. Baker and Hubbard (2000b) argue that this distinction is relevant to the makeor-buy decision (whether the shipper should use an internal or an external fleet): equipments that improve monitoring (resp. coordination) should lead to more (resp. less) integration. Using the same survey, they find supporting evidence for this prediction.

\subsection{Dynamics of contracts}

Finally, a few papers have tried to take the predictions of dynamic contract theory to data. This is a difficult task, if only because the theory is often inconclusive or relies on very strong assumptions that are difficult to maintain within an applied framework ${ }^{31}$. Still, interesting insights have emerged from this line of work.

Three types of models have been considered in the literature. One is the pure model of repeated adverse selection; a second one considers repeated moral hazard; finally, a couple of papers have recently been devoted to empirical testing of models entailing symmetric learning.

\footnotetext{
${ }^{30}$ In particular, this cannot be due to optimal risk sharing as younger firms tend to be smaller than older firms.

${ }^{31}$ For instance, most papers in the field assume that agents cannot freely save or borrow, so that the dynamics of their consumption can be fully monitored by the principal (whether the latter is an employer, a landlord or an insurance company). When this assumption is relaxed, the models typically use very specific preferences (such as CARA with monetary cost of effort) in order to guarantee that income effects do not matter. For a detailed discussion in a moral hazard context, see Chiappori et al (1994).
} 
Dynamic models of asymmetric information An important contribution is due to Dionne and Doherty (1994), whose model of repeated adverse selection with one-sided commitment transposes previous work by Laffont and Tirole (1990) to a competitive framework. The key testable prediction is that in a repeated adverse selection framework of this kind, whenever commitment is possible for the insurer, then optimal contracts entail experience rating and exhibit an "highballing" property - i.e., the insurance company makes positive profits in the first period, compensated by low, below-cost second period prices. Dionne and Doherty test this property on Californian automobile insurance data. According to the theory, when contracts with and without commitment (from the insurer) are simultaneously available, contracts entailing commitments will typically attract low risk agents. The presence of highballing is empirically characterized by the fact that the loss to premium ratio should rise with the cohort age. If insurance companies are classified according to their average loss per vehicle (which reflects the "quality" of their portfolio of insurees), one expects the premium growth to be negative for the best quality portfolios; in addition, the corresponding slope should be larger for firms with higher average loss ratios. This prediction is confirmed by the data. Insurance companies are classified into three subgroups. The slope coefficient is negative and significant for the first group (with lowest average loss), positive and significant for the third group, non significant for the intermediate group. Dionne and Doherty conclude that the "highballing" prediction is not rejected.

In a recent contribution, Margiotta and Miller (1998) analyze a dynamic model of managerial compensation under moral hazard. Their framework is reminiscent of that introduced by Fudenberg et al. (1990): the manager's utility function exhibits constant absolute risk aversion, so that wealth effects do not make the analysis untractable. They estimate the model from longitudinal data on returns to firms and managerial compensations. Obviously, the dynamic nature of the data introduces more robustness into the estimations, as compared to simple cross-sectional analysis. In particular, it allows to mitigate an obvious selection problem with cross-sectional data: the level of incentives provided by the manager's contract should be endogenous to the firm's situation, and the latter may impact the outcome in a non observable way. The conclusions drawn by Margiotta and Miller are particularly interesting in view of the Jensen-Murphy controversy. They find that although the benefits of providing incentives are large, the costs are small, in the sense that even a relatively small fraction of the firm's shares is generally sufficient to induce the required level of effort.

Symmetric learning Finally, several works test a model of symmetric but incomplete information and learning. The basic reference, here, is the labor contract paper by Harris and Holmstrom (1992), in which the employer and the employee have identical priors about the employee's ability and learn at the same pace from the employee's performance. This setting has been applied with success to labor contracts, but also to long-term insurance relationships. 
An application to internal labor markets is proposed by Chiappori, Salanié and Valentin (1999). Their model borrows the two main ingredients of the Harris and Holmstrom framework, namely symmetric learning and downwards rigidity of wages (the latter being explained either by risk sharing considerations as in the initial model, or by hold-up problems and contractual incompleteness). They show that optimal contracts should then exhibit a "late beginner" effect: if two agents, $\mathrm{A}$ and $\mathrm{B}$, are at the same wage level at date 0 and at date 2 , but A's wage at date 1 was higher, then $B$ has better future prospects for date 3 and later. They test this prediction on data on contracts and careers within a French public firm. Interestingly enough, carreers, in this context, must be analyzed as sequences of discrete promotions, a feature that requires specific econometric tools. The results very strongly confirm the predictions: the "late beginner" effect appears as a crucial feature of careers in the context under consideration.

Recently, the same type of model has been applied to life insurance contracts by Hendel and Lizzeri (2000). They exploit an interesting data base of contracts, that includes information on the entire profile of future premiums. Some contracts involve commitment from the insurer, in the sense that the evolution of premia will not be contingent on the insuree's health status, whereas under the other contracts future premiums are increased if the insuree's health condition deteriorates. According to the theory, commitment implies front loading (initial premiums should be higher than without commitment, since they include an insurance premium against the reclassification risk) and a lower lapsation rate (a fraction of the agents whose health has actually deteriorated, would be strictly worse off if they were to change company). These predictions are satisfied by existing contracts. Even more interesting is the fact that this confirmation only obtains for general life insurance. Accidental death contracts exhibit none of the above features, as one would expect given that learning considerations are much less prominent.

Finally, in such a context, any friction that limits the agent's mobility between contracts is welfare improving, since the precommitment of insurees to stay in the pool helps mitigate the uninsurability of the reclassification risk. This idea is exploited by Crocker and Moran (1997) in a study of employer provided health insurance contracts, for which precommitment is proxied by the difficulty for workers of switching jobs. They show that when employers must offer the same contract to all of their workers, then the optimal contract exhibits a coverage limitation that is inversely proportional to the degree of employee job lock. If on the other hand employers are able to offer multiple contracts which experience-rate the insurees, then the optimal contract exhibits full coverage of medical expenditures, albeit at second period premiums that partially reflect each individual's observable health status. Crocker and Moran confirm these predictions on data on insurance coverages using proxies for job lock: the insurance contracts associated with firms who offer a single policy exhibit coverage limitations which are decreasing in the amount of employee job lock, and those firms offering multiple plans to their workforce have higher levels of coverage which are insensitive to the degree of job lock. 


\section{Conclusion}

"Data! data! data!" he cried impatiently. "I can’t make bricks without clay."

Arthur Conan Doyle, The Adventure of the Copper Beeches.

We hope this survey has shown that the econometrics of contracts is a very promising and burgeoning field. While empirical testing of the theory of contracts started in the eighties, most of the papers we have surveyed were indeed written in the last five years. For a long time, econometricians could be heard echoing Sherlock Holmes's complaint about lack of data on contracts. It is true that some researchers have gone far to find their data (as far as Renaissance Tuscany for Ackerberg-Botticini (1999)). Still, it has proven much less difficult than expected to find data that is amenable to econometric techniques. In fact, we draw the impression from Bresnahan's (1997) earlier World Congress survey that the situation is somewhat worse in industrial organization.

It is still true that many papers in this field use similar data and/or focus on similar problems, as shown by the number of papers on sharecropping or natural gas we surveyed. We would certainly want to see wider-ranging empirical work in the future. Insurance data is very promising in that respect, as it is fairly standardized, comes in large data sets and can be used to test many different theories. It can also be hoped that in the future, firms will be less averse to opening their personnel data to researchers, as they did to Baker-GibbsHolmstrom (1994a, 1994b).

Our conclusion on the importance of incentive effects echoes that of Prendergast (1999) for incentives in firms: the recent literature, as surveyed in section 2 , provides very strong evidence that contractual forms have large effects on behavior. As the notion that "incentives matter" is one of the central tenets of economists of every persuasion, this should be comforting to the community. On the other hand, it raises an old puzzle: if contractual form matters so much, why do we observe such a prevalence of fairly simple contracts? More generally, the question asked in section 3 is whether observed contracts take the form predicted by the theory. As we have seen, the evidence is more mixed in that regard. However, it is reassuring to see that papers that control adequately for selection and endogeneity bias have generally been more supportive of the theory.

Throughout this survey, we emphasized the crucial role of the selection, matching and contract endogeneity issues. These problems are prevalent in the two approaches we distinguish - i.e., whether one is testing for the optimality of contracts or for the behavioral impact of given contractual forms. It can be argued that selection issues are probably even more difficult to address in the first case, because our theoretical understanding of situations involving "realistic" forms of unobserved heterogeneity is often very incomplete. To take but one example, Rothchild and Stiglitz's celebrated model of insurance under adverse selection (1976) assumes identical preferences across agents. Should risk aversion differ across insurees as well, then the shape of the equilibrium contract 
is not fully known for the moment ${ }^{32}$. It is however safe to predict that where the theory cannot be reconciled with the facts, new and improved models will emerge. Thus we hope that some econometricians will be inspired by this survey to contribute to the growing literature on testing of contract theory, while negative empirical findings may prompt some theorists to improve the theory itself. As an example of this potentially fruitful dialog between theorists and econometricians, the empirical findings by Chiappori-Salanié $(1997,2000)$ and others that the standard models of insurance do not fit the data well in some insurance markets has led Chassagnon and Chiappori (1997), de Meza and Webb (2001) and Jullien, Salanié and Salanié (2000) to propose new models of insurance that are based on a combination of moral hazard and adverse selection. Similarly, new tools have recently been developed, that allow to tackle the possible coexistence of several types of unobserved heterogeneity ${ }^{33}$. We hope to see more of this interplay between theory and testing in the future.

\section{References}

Ackerberg, D. and M. Botticini (forthcoming), "Endogenous Matching and the Empirical Determinants of Contract Form", Journal of Political Economy, forthcoming.

Aggarwal, R. and A. Samwick (1999), "The Other Side of the Trade-off: The Impact of Risk on Executive Compensation", Journal of Political Economy, 107, 65-105.

Akerlof, G. (1970), "The Market for 'Lemons': Quality Uncertainty and the Market Mechanism", Quarterly Journal of Economics, 84, 488-500.

Allen, D. W., and D. Lueck (1992), "Contract Choice in Modern Agriculture: Cash Rent Versus Cropshare", Journal of Law and Economics, 35, 397-426.

Allen, D. W., and D. Lueck (1993), "Transaction Costs and the Design of Cropshare Contracts", RAND Journal of Economics, 24 1, 78-100.

Allen, D. W., and D. Lueck (1998), "The Nature of the Farm", Journal of Law and Economics, 41, 343-86.

Allen, D. W., and D. Lueck (1999), "The Role of Risk in Contract Choice", Journal of Law, Economics and Organization, 15 3, 704-36.

Ausubel, L (1999), " Adverse Selection in the Credit Card Market", Mimeo, University of Maryland.

Bach, K. (1998), Negativauslese und Tarifdifferenzierung im Versicherungssektor, DUV, Schesslitz.

Baker, G., M. Gibbs, and B. Holmstrom (1994a), "The Internal Economics of the Firm: Evidence from Personnel Data", Quarterly Journal of Economics, 109, 881-919.

\footnotetext{
${ }^{32}$ See, however, Landsberger and Meilijson (1999).
}

${ }^{33}$ See Rochet and Stole in this volume. 
Baker, G., M. Gibbs, and B. Holmstrom (1994b), "The Wage Policy of a Firm", Quarterly Journal of Economics, 109, 921-955.

Baker, G., and T. Hubbard (2000a), "Contractibility and Asset Ownership: On-Board Computers and Governance in U.S. Trucking", NBER Working Paper 7634.

Baker, G., and T. Hubbard (2000b), "Make vs Buy in Trucking: Asset Ownership, Job Design and Information", mimeo Harvard.

Baker, G., and T. Hubbard (2001), "Empirical Strategies in Contract Economics: Information and the Boundary of the Firm", American Economic Review, 91, 189-194.

Bandiera, O. (2001), "On the Structure of Tenancy Contracts: Theory and Evidence from 19th Century Rural Sicily", CEPR working paper 3032.

Banerjee, A. and E. Duflo (1999), "Reputation Effects and the Limits of Contracting: A Study of the Indian Software Industry", mimeo MIT.

Banerjee, A. P. Gertler and M. Ghatak (2002), "Empowerment and Efficiency: Tenancy Reform in West Bengal", Journal of Political Economy, 110, 239-80.

Bertrand, M. and S. Mullainathan (2001), "Are CEOs Rewarded for Luck? The Ones Without Principals Are", Quarterly Journal of Economics, 116, 901-932.

Bolduc, D., Fortin, B., F. Labrecque and P. Lanoie (forthcoming), "Workers' Compensation, Moral Hazard and the Composition of Workplace Injuries", Journal of Human Resources, forthcoming.

Boyer, M., et G. Dionne (1989) : "An Empirical Analysis of Moral Hazard and Experience Rating", Review of Economics and Statistics, 71, 12834 .

Bresnahan, T. (1997), "Testing and Measurement in Competition Models", in Advances in Economics and Econometrics: Theory and Applications, volume 3, D. Kreps and $\mathrm{K}$. Wallis eds.

Browne, M., and R. Puelz (1999), "The Effect of Legal Rules on the Value of Economic and Non-Economic Damages and the Decision to File", Journal of Risk and Uncertainty, 18, 189-213.

Brugiavini, A. (1993), "Uncertainty Resolution and the Timing of Annuity Purchase", Journal of Public Economy, 50, 31-62.

Cardon, J., and I. Hendel (2001), "Asymmetric Information in Health Insurance : Evidence From the National Health Expenditure Survey', RAND Journal of Economics, 32, 408-27.

Cawley. J. and T. Philipson (1999), "An Empirical Examination of Information Barriers to Trade in Insurance", American Economic Review, 89, 827-846.

Chevalier, J. and G. Ellison (1997), "Risk Taking by Mutual Funds as a Response to Incentives", Journal of Political Economy, 105, 1167-1200.

Chevalier, J. and G. Ellison (1999), "Career Concerns of Mutual Fund Managers", Quarterly Journal of Economics, 114, 389-432.

Chassagnon, A., and P.A. Chiappori (1997), "Insurance under Moral Hazard and Adverse Selection: The Competitive Case", mimeo, DELTA. 
Chiappori, P.A. (2000), "Econometric Models of Insurance under Asymmetric Information", in G. Dionne, ed., Handbook of Insurance, North Holland.

Chiappori, P. A., J. Abbring, J. Heckman and J. Pinquet (2001), "Testing for Adverse Selection versus Moral Hazard from Dynamic Data", Mimeo, University of Chicago.

Chiappori, P. A., F. Durand and P.Y. Geoffard (1998), "Moral Hazard and the Demand for Physician Services: First Lessons from a French Natural Experiment", European Economic Review, 42, 499-511.

Chiappori, P. A., P.Y. Geoffard and E. Kyriadizou (1998), "Cost of Time, Moral Hazard, and the Demand for Physician Services", Mimeo, University of Chicago.

Chiappori, P.A., I. Macho, P. Rey and B. Salanié (1994), "Repeated Moral Hazard: The Role of Memory and Commitment, and the Access to Credit Markets", European Economic Review, 38, 1527-1553.

Chiappori, P.A. and B. Salanié (1997), "Empirical Contract Theory: The Case of Insurance Data", European Economic Review, 41, 943-950.

Chiappori, P.A. and B. Salanié (2000), "Testing for Asymmetric Information in Insurance Markets", Journal of Political Economy, 108, 56-78.

Chiappori, P.A., B. Salanié and J. Valentin (1999), "Early Starters vs Late Beginners ", Journal of Political Economy, 107, 731-760.

Cochrane, J. (1991), "A Simple Test of Consumption Insurance", Journal of Political Economy, 99, 957-976.

Core, J., and W. Guay (2000), "The Other Side of the Trade-off: The Impact of Risk on Executive Compensation: a Comment", mimeo, Wharton School.

Crocker, K. and S. Masten (1988), "Mitigating Contractual Hazards: Unilateral Options and Contract Length", Rand Journal of Economics, 19, 327343.

Crocker, K. and S. Masten (1991), "Pretia Ex Machina? Prices and Process in Long-term Contracts", Journal of Law and Economics, 34, 69-99.

Crocker, K. and J. Moran (1997), "Commitment and the Design of Optimal Agreements: Evidence from Employment-Based Health Insurance Contracts", Mimeo, U. of Michigan.

Crocker, K. and K. Reynolds (1993), "The Efficiency of Incomplete Contracts: An Empirical Analysis of Air Force Engine Procurement", RAND Journal of Economics, 24, 126-146.

Dahlby, B. (1983), "Adverse Selection and Statistical Discrimination: An Analysis of Canadian Automobile Insurance", Journal of Public Economics, 20, 121-130.

de Meza, D. and D. Webb (2001), "Advantageous Selection in Insurance Markets", RAND Journal of Economics, 32, 249-262.

Dionne, G., and N. Doherty (1994), "Adverse Selection, Commitment and Renegotiation: Extension to and Evidence from Insurance Markets', Journal of Political Economy, 102-2, 210-35

Dionne, G., and R. Gagné (2001), "Deductible Contracts Against Fraudulent Claims: Evidence From Automobile Insurance", Review of Economics and 
Statistics, 83, 290-301.

Dionne, G., C. Gouriéroux and C. Vanasse (1998), "Evidence of Adverse Selection in Automobile Insurance Markets", mimeo.

Dionne, G., C. Gouriéroux and C. Vanasse (2001), "Testing for Adverse Selection in the Automobile Insurance Market: A Comment", Journal of Political Economy, 109, 444-453.

Dionne, G, and P. St-Michel (1991), "Worker's Compensation and Moral Hazard", Review of Economics and Statistics, 73, 236-44.

Dubois, P. (1999), "Moral Hazard, Land Fertility and Sharecropping in a Rural Area of the Philippines", CREST Working Paper 9930, forthcoming in the Journal of Development Economics.

Dubois, P. (2000a), "Assurance complète, hétérogénéité des préférences et métayage au Pakistan", Annales d'économie et de statistiques, 59, 1-36.

Dubois, P. (2000b), "Consumption Insurance with Heterogeneous Preferences: Can Sharecropping Help Complete Markets?", Mimeo, INRA Toulouse.

Ferrall, C. and B. Shearer (1999), "Incentives and Transactions Costs within the Firm: Estimating an Agency Model Using Payroll Records", Review of Economic Studies, 66, 309-38.

Finkelstein, A., and J. Poterba (2000), "Adverse Selection in Insurance Markets: Policyholder Evidence From the UK Annuity Market", NBER Working Paper W8045.

Fortin, B. and P. Lanoie (1992), "Substitution between Unemployment Insurance and Workers'Compensation", Journal of Public Economics, 49, 287312 .

Fortin, B. and P. Lanoie (1998), "Effects of Workers' Compensation: a Survey", CIRANO Scientific Series, Montréal, 98s-04.

Fortin, B., P. Lanoie and C. Laporte (1995), "Is Workers' Compensation Disguised Unemployment Insurance?", CIRANO Scientific Series, Montréal, 95s-48.

Friedman, B.M., and M.J. Warshawski (1990), "The Cost of Annuities: Implications for Savings Behavior and Bequests", Quarterly Journal of Economics, 420, 135-54.

Fudenberg, D., B. Holmstrom and P. Milgrom (1990), "Short-term Contracts and Long-term Agency Relationships", Journal of Economic Theory, $51,1-31$.

Gale, D., and M. Hellwig (1985), "Incentive-compatible debt contracts: the one-period problem", Review of Economic Studies, 52, 647-63.

Gagnepain, P. and M. Ivaldi (2001), "Incentive Regulatory Policies: The case of Public Transit Systems in France", mimeo.

Genesove, D. (1993), "Adverse Selection in the Wholesale Used Car Market", Journal of Political Economy, 104, 644-665.

Gibbons, R. and K. Murphy (1990), "Relative Performance Evaluation of Chief Executive Officers", Industrial and Labor Relations Review, 43, S30S51.

Gibbons, R., and M. Waldman (1999), "Careers in Organizations: 
Theory and Evidence", in Ashenfelter and Card, eds., Handbook of Labor Economics, Volume 3b, Chapter 36

Gouriéroux, C. (1999), "The Econometrics of Risk Classification in Insurance", Geneva Papers on Risk and Insurance Theory, 24, 119-139.

Gouriéroux, C., A. Monfort and A. Trognon (1984), "Pseudo-Maximum Likelihood Methods: Theory", Econometrica, 52, 681-700.

Hall, J. and J. Liebman (1998), "Are CEOs Really Paid Like Bureaucrats?", Quarterly Journal of Economics, 113, 653-691.

Hanssen, R. (2001), "The Effect of a Technological Shock on Contract Form: Revenue Sharing in Movie Exhibition and the Coming of Sound", mimeo.

Harris M. and B. Holmstrom (1982), "A Theory of Wage Dynamics", Review of Economic Studies, 49, 315-333.

Hart, O. (1995), Firms, Contracts, and Financial Structure, Oxford University Press.

Hart, O. and J. Tirole (1988), "Contract Renegotiation and Coasian Dynamics", Review of Economic Studies, 55, 509-40.

Haubrich, J. (1994), "Risk Aversion, Performance Pay, and the PrincipalAgent Model", Journal of Political Economy, 102, 258-276.

Hendel, I. and A. Lizzeri (2000), "The Role of Commitment in Dynamic Contracts : Evidence from Life Insurance", Working Paper, Princeton University.

Holly, A., L. Gardiol, G. Domenighetti and B. Bisig (1998), "An Econometric Model of Health Care Utilization and Health Insurance in Switzerland", European Economic Review, 42, 513-522.

Holmstrom, B. and P. Milgrom (1991), "Multitask Principal-Agent Analyses: Incentive Contracts, Asset Ownership and Job Design", Journal of Law, Economics and Organization, 7, 24-51.

Hubbard, T. (1999), "How Wide is the Scope of Hold-Up-Based Theories? Contractual Form and Market Thickness in Trucking", UCLA mimeo.

Hubbard, R. and R. Weiner (1991), "Efficient Contracting and Market Power: Evidence from the US Natural Gas Industry", Journal of Law and Economics, 34, 25-67.

Ivaldi, M. and D. Martimort (1994), "Competition under Nonlinear Pricing", Annales d'Economie et de Statistiques, 34, 72-114.

Jensen, M. and K. Murphy (1990), "Performance Pay and Top-Management Incentives", Journal of Political Economy, 98, 225-264.

Joskow, P. (1985), "Vertical Integration and Long-Term Contracts: The Case of Coal-Burning Electric Generation Plants", Journal of Law, Economics and Organization, $1,33-80$.

Joskow, P. (1987), "Contract Duration and Relationship-Specific Investments: Empirical Evidence from Coal Markets", American Economic Review, $77,168-185$

Jullien, B., B. Salanié and F. Salanié (2000), "Screening Risk-Averse Agents Under Moral Hazard", mimeo.

Kaplan, S. and P. Strömberg (1999), "Financial Contracting Theory Meets the Real World: Evidence From Venture Capital Contracts", mimeo. 
Laffont, J.J. (1997), "Game Theory and Empirical Economics: The Case of Auction Data", European Economic Review, 41, 1-35.

Laffont, J.-J. and M. Matoussi (1995), "Moral Hazard, Financial Constraints and Sharecropping in El Oulja", Review of Economic Studies, 62, 381399 .

Laffont, J.-J. and J. Tirole (1990), "Adverse Selection and Renegotiation in Procurement", The Review of Economic Studies, 57 4., 597-625

Landsberger, M. and I. Meilijson (1999), "A General Model of Insurance under Adverse Selection", Economic Theory, 14, 331-52.

Lavergne, P., and A. Thomas (2000), "Semiparametric Estimation and Testing in a Model of Environmental Regulation with Adverse Selection", mimeo, INSEE, Paris.

Lazear, E. (2000), "Performance Pay and Productivity", American Economic Review, 90, 1346-1361.

Lemmon, M., J. Schallheim and J. Zender (2000), "Do Incentives Matter? Managerial Contracts for Dual-Purpose Funds", Journal of Political Economy, 108, 273-99.

MacLeod, B., and D. Parent (1999), "Job Characteristics and the Form of Compensation", Research in Labor Economics, 18, 177-242.

Manning, W., J. Newhouse, N. Duan, E. Keeler and A. Leibowitz (1987), "Health Insurance and the Demand for Medical Care: Evidence from a Randomized Experiment," American Economic Review, 77, 251-277.

Margiotta, M. and R. Miller (2000), "Managerial Compensation and the Cost of Moral Hazard", International Economic Review, 41, 669-719.

Masten, S. and K. Crocker (1985), "Efficient Adaptation in Long-term Contracts: Take-or-pay Provisions for Natural Gas", American Economic Review, 75, 1083-1093.

McMillan, J. and C. Woodruff (1999), "Interfirm Relationships and Informal Credit in Vietnam", Quarterly Journal of Economics, 114, 1285-1320.

Monteverdi, K. and D. Teece (1982), "Supplier Switching Costs and Vertical Integration in the Automobile Industry", Bell Journal of Economics, 13, 206-213.

Murphy, K. (1999), "Executive Compensation", in Handbook of Labor Economics, vol. 3, O. Ashenfelter and D. Card eds, North-Holland.

Oyer, P. (1998), "Fiscal Year End and Nonlinear Incentive Contracts: the Effect on Business Seasonality", Quarterly Journal of Economics, 113, 149-85.

Paarsch, H. and B. Shearer (1999), "The Response of Worker Effort to Piece Rates: Evidence from the British Columbia Tree-Planting Industry", Journal of Human Resources, 34, 643-667.

Paarsch, H. and B. Shearer (2000), "Piece Rates, Fixed Wages and Incentive Effects: Statistical Evidence from Payroll Records", International Economic Review, 41, 59-92.

Prendergast, C. (1999), "The Provision of Incentives in Firms", Journal of Economic Literature, 37, 7-63.

Puelz, R. and A. Snow (1994), "Evidence on Adverse Selection : Equilibrium Signalling and Cross-Subsidization in the Insurance Market", Journal 
of Political Economy, 102, 236-57.

Richaudeau, D. (1999), "Automobile Insurance Contracts and Risk of Accident: An Empirical Test Using French Individual Data", The Geneva Papers on Risk and Insurance Theory, 24, 97-114.

Rosen, S. (1992), "Contracts and The Market for Executives", in Contract Economics, L. Werin and H. Wijkander eds, Basil Blackwell.

Rothschild, M. and J. Stiglitz (1976), "Equilibrium in Competitive Insurance Markets", Quarterly Journal of Economics, 90, 629-649.

Shelanski, H. and P. Klein (1995), "Empirical Research in Transaction Cost Economics: A Review and Assessment", Journal of Law, Economics and Organization, 11,335-361.

Slade, M. (1996), "Multitask Agency and Contract Choice: An Empirical Exploration", International Economic Review, 37, 465-486.

Shearer, B. (1999), "Piece Rates, Fixed Wages and Incentives: Evidence from a Field Experiment", Mimeo, Laval University.

Stiglitz, J. (1974), "Incentives and Risk Sharing in Sharecropping", Review of Economic Studies, 41, 219-255.

Stiglitz, J., and A. Weiss (1981), "Credit Rationing in Markets with Imperfect Information", American Economic Review, 71, 393-410.

Timmins, C. (2000), "Measuring the Dynamic Efficiency Costs of Regulators' Preferences: Municipal Water Utilities in the Arid West", forthcoming in Econometrica.

Toivanen, O., and R. Cressy (1998), "Is There Adverse Selection on the Credit Market?", Mimeo, Warwick.

Townsend, R. (1994), "Risk and Insurance in Village India", Econometrica, 62, 539-591.

Vuong, Q. (1989), "Likelihood Ratio Tests for Model Selection and NonNested Hypotheses", Econometrica, 57, 307-334.

Whinston, M. (2000), "On the Transaction Cost Determinants of Vertical Integration", mimeo, Northwestern University.

Whinston, M. (2001), "Assessing the Property Rights and Transaction Cost Theories of Firm Scope", American Economic Review, 91, 184-188.

Williamson, O. (1975), Markets and Hierarchies: Analysis and Antitrust Implications, The Free Press.

Williamson, O. (1985), The Economic Institutions of Capitalism: Firms, Markets, Relational Contracting, The Free Press.

Williamson, O. (1996), The Mechanisms of Governance, Oxford University Press.

Wolak, F. (1994), "An Econometric Analysis of the Asymmetric Information, Regulator-Utility Interaction", Annales d'Economie et de Statistiques, 34, 13-69.

Young, P. and M. Burke (2001), "Competition and Custom in Economic Contracts: A Case Study of Illinois Agriculture", American Economic Review, 91, 559-573. 